\title{
Organization Capital and the Cross-Section of Expected Returns
}

\author{
Andrea L. Eisfeldt* \\ Northwestern University
}

\author{
Dimitris Papanikolaou ${ }^{\dagger}$ \\ Northwestern University
}

\section{November 2008}

\begin{abstract}
This paper studies the unique risk characteristics of organization capital. Using a stock measure of organization capital based on readily available accounting data, we find that firms with more organization capital relative to their industry peers outperform firms with less organization capital by $4.7 \%$ per year. A long short portfolio based on the ratio of the stock of organization capital to total assets within industries has a Sharpe ratio of 0.57. We develop a parsimonious model featuring what we argue are the two most salient features of organization capital, namely that it is firm specific and that it is partially embodied in firms' labor input and thus cannot be wholly owned by shareholders. The model economy illustrates the sensitivity of organization capital to economic restructuring and the resulting risk premia required for high organization capital firms.
\end{abstract}

${ }^{*}$ Department of Finance, Kellogg School of Management, Northwestern University, 2001 Sheridan Road, Evanston, IL, 60208. Phone: (847) 491-7843. Email: a-eisfeldt@northwestern.edu.

${ }^{\dagger}$ Department of Finance, Kellogg School of Management, Northwestern University, 2001 Sheridan Road, Evanston, IL, 60208. Phone: (847) 491-7704. Email: dpapanikolaou@kellogg.northwestern.edu. 


\section{Introduction}

We find that firms with more organization capital relative to their industry peers outperform firms with less organization capital by $4.7 \%$ per year. Organization capital measures the accumulated stock of organization "know-how," a collection of production and sales processes that are unique to the firm. Examples include employee incentive and training programs, distribution systems, and internal communication processes. These systems comprise an additional factor of production which is often ignored because it is difficult to measure, yet this factor is likely to be important 1 Moreover, organization capital may have risk characteristics distinct from that of physical capital. Being intangible, organization capital lacks a physical presence and instead enhances the productivity of the match between physical capital and labor. It is highly specific and likely to depreciate substantially if the match is dissolved. Moreover, some of the rents from organization capital must be split with the labor in which it is embodied. Therefore, firms with more organization capital may be riskier and thus require higher expected returns.

We measure organization capital by accumulating firms' Selling, General, and Administrative (SG\&A) Expense. Lev and Radhakrishnan (2004) argue that the SG\&A expense includes most of the expenditures that generate organization capital $\left.\right|^{2} \mathrm{We}$ treat these SG\&A payments as investment in organization capital and form a stock by accumulating this investment using the perpetual inventory method. Other attempts to measure organization capital have done so by measuring it as a residual from a structural model. While this methodology avoids some of the difficulties inherent in measuring intangibles, the resulting estimates are likely to be quite sensitive to the model specification. In contrast, our direct measure is model independent and recognizes that a substantial part of the SG\&A expense yields long run benefits and

\footnotetext{
${ }^{1}$ Atkeson and Kehoe (2005) find that even for manufacturing firms payments to intangible capital constitute $8 \%$ of output. Hall (2000a) argues that e-capital arising from the use of skilled labor contributed substantially to the high value of corporate capital in the 1990's.

${ }^{2}$ Lev and Radhakrishnan highlight IT outlays, employee training costs, brand enhancement activities, payment to systems and strategy consultants, and the cost of setting up and maintaining internet-based supply and distribution channels as key inputs to organization capital which are included in the SG\&A expense.
} 
thus can be viewed as accumulating a durable factor in production 3 Moreover, we find that the relationship between SG\&A expenditures and firm level characteristics is remarkably similar to that of physical capital expenditures, consistent with our idea that resources allocated to this expense can be considered investment.

Using our measure of organization capital to sort firms into portfolios, we find that firms in the highest quintile outperform firms in the lowest quintile by $4.7 \%$ per year. A long short portfolio based on this sort has a Sharpe ratio of 0.57. This difference in expected returns is not explained by the CAPM, or the Fama and French (1993) three factor model, and our portfolios do not load in a systematic way on these factors. We show that our portfolios based on the contribution of organization to total capital do not vary systematically in terms of market capitalization. However, as one might expect, the high organization capital portfolio has a higher market to book ratio, a lower ratio of PP\&E to total assets and lower leverage than the low organization capital portfolio.

We develop a model that captures two salient features of organization capital. First, part of the knowledge that organization capital represents is embodied in workers who can transfer this knowledge when they leave the firm, and thus these workers will effectively own some of the organization capital. Second, the specificity of organization capital means that shareholders can capture some, but not all, of the rents it accrues. Firms differ in their accumulated stock of organization capital, and in the productivity of that organization capital. Our model features two aggregate shocks. The first is a neutral technological shock that affects all capital symmetrically. The second captures the level of frontier organization capital technology. This frontier technology determines the productivity of organization capital deployed in new firms. We assume that shareholders place a high marginal value on resources available in states in which the frontier technology improves. When the frontier technology improves, resources are reallocated from old firms into new firms and this restructuring is costly. It is the differential sensitivity to the frontier technology that generates dispersion in risk premia. An improvement in the fron-

\footnotetext{
${ }^{3}$ The Bureau of Economic Analysis uses a similar methodology to construct a stock of Research and Development capital, see Sliker (2007).
} 
tier technology increases workers' outside option which reduces shareholders' share of profits in existing firms. The value of firms with high levels of organization capital is more sensitive to this shock and thus these firms command higher risk premia.

We build on a growing literature which studies the properties of organization capital and highlights its unique features. To our knowledge, we are the first to study the distinguishing risk characteristics of organization capital in an economy where this input is modeled explicitly, and the first to explore the returns to organization capital using a measure of its stock constructed from accounting data 4 Our stock measure of organization capital is built on that in Lev and Radhakrishnan (2004), who use flow data on SG\&A expenses to construct more accurate estimates of corporate value. The stock measure we employ is analogous to that used by the BEA to construct a measure of R\&D capital from R\&D expenses. Lev (2001), Blair and Wallman (2001), and Black and Lynch (2005) discuss the concept of organization capital and the difficulties involved in measuring it.

Our model of firms' accumulation of organization capital as a by-product of production loosely follows Atkeson and Kehoe (2005), who build on ideas in Rosen (1972), and Ericson and Pakes (1995). Atkeson and Kehoe convincingly argue that organization capital is an important input into firms' production and measure its contribution using their structural model. As in their model, our economy also features a process describing the evolution of the frontier organization capital technology, or what they call a "blueprint" 5 In contrast to their model, however, we model organization capital as being partially embodied in the workers or managers of the firm, so that shareholders cannot extract all of the rents accruing to this type of firm specific capital. We do this in the spirit of Prescott and Visscher (1980), who describe how organization capital in the form of knowledge about personnel and firm specific human capital can yield a theory of the firm with implications for firm growth and size 6

\footnotetext{
${ }^{4}$ See Hansen, Heaton, and Li (2004) for a related study of the risk characteristics of intangible capital. They build on methods used in McGrattan and Prescott (2000), Atkeson and Kehoe (2005), and Hall $(2000 \mathrm{a}, 2001)$ to measure intangible capital, and rely on the idea that appropriately risk adjusted investment returns to total capital should be equated across firms.

${ }^{5}$ See also Jovanovic and Rousseau (2001) for evidence of vintage specific organization capital.

${ }^{6}$ Chowdry and Garmaise (2003) build on these ideas and develop a model of intrafirm communication to derive implications for managerial turnover and compensation.
} 
In our model, the arrival of a new frontier technology improves the outside option of workers and managers who can depart and take some of the organization capital with them. In related and complementary work, Lustig, Syverson, and Van Nieuwerburgh (2008), focus on this division of rents between shareholders and managers: 7 They explicitly model the contracting problem between shareholders and managers and deliver implications consistent with the observed rise in inequality of managerial compensation and pay for performance sensitivity, and the accompanying decrease in labor market reallocation.

Our model also aims to capture the risks inherent to organization capital during times of economic restructuring. We believe that the value of organization capital intensive firms may be particularly sensitive to periods of intense corporate reallocation and that these periods are distinct from economic downturns. In support of these ideas, Caballero and Hammour (2001, 2005), and Eisfeldt and Rampini (2006) point out that restructuring and capital reallocation actually tend to be positively correlated with GDP growth 8 We also argue that investors will place a high value on resources in states where corporate restructuring must occur. Foster, Haltiwanger, and Krizan (2001) show that reallocation is an integral determinant of productivity growth occurring through new plants which require a costly period of learning and selection. In general equilibrium frameworks, Papanikolaou (2008) and Eisfeldt and Rampini (2007) study the related idea that investors will place a high value on resources available in states with positive investment opportunities. In our model of organization capital, improvements in organization efficiency represent positive investment opportunities which require costly reallocation.

We feel that our model captures several important features of organization capital which have been highlighted in the prior literature, namely, that it is intangible, firm

\footnotetext{
${ }^{7}$ See also related work by Jovanovic and Rousseau (2008)

${ }^{8}$ See also Maksimovic and Phillips (2001) for related evidence at the industry level. Caballero (2007) provides a detailed exploration of the role of specific capital in economic restructuring. Davis, Haltiwanger, and Schuh (1996) rigorously document the stylized facts of reallocation in the form of manufacturing job flows. Hall (2000b) explores an alternative model of restructuring, where reorganization is a form of investment which lowers contemporaneous output. Organization capital might be risky in this type of economy as well, but such risk would be well captured by market beta.
} 
specific, not wholly owned by firms' shareholders but embodied in the workforce, and that as a result of these unique features it will have risk characteristics distinct from those of physical capital.

\section{Empirical Results}

As an intangible asset, organization capital is difficult to measure. This is well recognized, and previous authors have used structural models to impute the value of intangibles. Instead, we use expenditures on SG\&A to construct a measure of organization capital from readily available accounting data. The following simple perpetual inventory equation describes how we construct our measure of the stock of organization capital:

$$
O_{i, t}=(1-\delta) O_{i, t-1}+S G A_{i, t}
$$

To the extent that some SG\&A expenditures do not constitute investment in organization capital we will be measuring this capital with error. We are trading off this cost with the benefit that we do not rely on a specific structural model for our measure. Our measure of investment in organization capital follows Lev and Radhakrishnan (2004). Lev and Radhakrishnan (2004) and Lev (2001) present detailed arguments and examples of how resources allocated to this expense yield improvements in employee incentives, internal communication systems, distribution systems, and other examples of organization capital. Our measure accumulates these expenditure and forms an organization capital stock. This stock measure recognizes that such expenditures yield long run productivity and output gains, much like capital expenditures accumulated in physical capital do.

We sort firms every year into portfolios based on the share of organization capital to total assets within industries. The characteristics of these portfolios are shown in Table 1. The characteristics of these portfolios are consistent with interpreting the stock we construct as organization capital. The fraction of market value represented by each of the five portfolios we construct is approximately equal, although the highest organization capital firms represent a smaller fraction of total capitalization. 
The table also shows that high organization capital firms tend to have lower PP\&E relative to total assets, and lower leverage, which is what one might expect. On the other hand, the book to market ratio for the median firm in any given portfolio does not vary much with the organization capital of that portfolio. Table 2 provides further evidence that expenditures on SG\&A may reasonably be considered a form of investment. The table describes the behavior of these expenditures and shows that they exhibit many of the same properties as capital expenditures. For example, SG\&A expenditures tend to be high following high sales and cash flow realizations. They are related positively to lagged $Q$, where assets have been adjusted to reflect the value of organization capital, but negatively related to leverage.

To implement the law of motion in Equation (1) we must choose an initial stock and a depreciation rate. Since it is relative values of organization capital that we are most interested in, we set the initial stock to zero. For most of our analysis, we use a depreciation rate of $20 \%$, which implies that past investments depreciate quickly and more recent expenditures have much more impact on our measure. Finally, we must decide what to do with missing values in the SG\&A expense, and we set these missing values to zero.

Table 3 documents our main results. We construct 5 portfolios of firms based on their level of organization capital relative to total assets within their Fama and French (1997) industries. Sorting within industries recognizes the fact that the composition of the SG\&A expense is likely to vary across industries. Portfolios are rebalanced annually, and the transition probabilities are given in Table 4 . Notice that in terms of trading implementation, the portfolios are remarkably stable.

A portfolio which is long high organization capital firms and short low organization capital firms earns an excess return of $4.7 \%$ with a Sharpe ratio of 0.57 . The alpha of this long-short portfolio with respect to the CAPM is 5.5\%. The market beta of the high organization capital portfolio is actually lower than that of the low organization capital portfolio. This is consistent with the idea that restructuring, to which organization capital is particularly sensitive, may actually be procyclical. Figure 1 plots returns of the portfolio which is long high organization capital firms and short low organization capital firms versus the turnover in Property, Plant and 
Equipment series constructed in Eisfeldt and Rampini (2006). The correlation between the two series is $-29 \%$. This is consistent with the idea that firms with a lot of organization capital perform relatively poorly in periods of restructuring. We formalize this intuition in Section 3.

We also examine whether the Fama and French (1993) model can explain the dispersion in risk premia due to differences in organization capital. In fact, the high organization capital portfolio actually has a slight growth tilt. Table 1 shows that the book to market ratio for the high organization capital portfolio is 0.50 versus 0.65 for the low organization capital portfolio. This makes sense because organization capital is valued by the market, but does not show up in book assets under current accounting standards. Given that the literature has documented that low book to market firms underperform relative to high book to market firms, controlling for this value premium increases the spread in returns between high and low organization capital firms. In fact, Table 3 shows that the alpha from the Fama and French three factor model exceeds that from the CAPM and is equal to $5.82 \%$. Thus, we conclude that firms with high organization capital relative to their industry peers seem to earn substantial risk premia which are unexplained by standard risk measures.

Furthermore, we perform a number of robustness checks. First, we show that our analysis is robust to our initialization scheme in Table 5. We repeat the analysis by dropping firms for which we have fewer than five previous non-missing observations of the SG\&A expense. Furthermore, we explore the sensitivity to our results to our choice for the depreciation rate in Table6. In both cases, the results are qualitatively and quantitatively similar to our benchmark results.

\section{Model}

In this section we develop a model of the formation and reallocation of organization capital. The model captures what we argue are two of the most salient features of organization capital, namely that it is firm specific and that it is partially embodied in firms' labor input and thus cannot be wholly owned by firms' shareholders. 


\subsection{Information}

The information structure obeys standard technical assumptions. Specifically, there exists a complete probability space $(\Omega, \mathcal{F}, \mathcal{P})$ supporting the vector of independent Brownian motions $Z_{t}=\left(Z_{t}, Z_{t}^{x}, Z_{t}^{\varepsilon_{i}}\right) . \mathcal{P}$ is the corresponding Wiener measure, and $\mathcal{F}$ is a right-continuous increasing filtration generated by $\mathrm{Z}$.

\subsection{Technology}

There is a continuum of firms which produce a common output good using capital $(K)$ and their current stock of organization capital $(\mathcal{O})$. The total output created by firm $i$ is given by:

$$
y_{i, t}=\theta_{t} K+\theta_{t} \exp \left(\varepsilon_{i, t}\right) \mathcal{O}_{i t}
$$

For simplicity, and to focus on the distribution of organization capital, we will assume that $K$ is constant across all firms and over time. A firm's organization capital measures the accumulated stock of firm specific knowledge about the production process and its specialized production, distribution, and sales systems, and enables the firm to produce a higher level of output for a given unit of physical capital. All firms are subject to a common technology shock $\theta$ which evolves according to

$$
d \theta_{t}=\mu_{\theta} \theta_{t} d t+\sigma_{\theta} \theta_{t} d Z_{t}
$$

Each firm's effective organization capital depends on the efficiency of that firm's organization $(\varepsilon)$ and the firm's stock of organization capital $(\mathcal{O})$. The efficiency of the firm's organization evolves according to

$$
d \varepsilon_{i, t}=-\kappa_{\varepsilon} \varepsilon_{i, t} d t+\sigma_{\varepsilon} d Z_{t}^{\varepsilon_{i}}
$$

A firm's accumulated stock of organization capital grows over time via learning by doing, but also may depreciate. We have in mind that as firms' operating environment changes, some specific organization capital may actually hinder its activities. Organization capital grows faster in firms with higher efficiency. This assumption 
is not crucial, but allows for dynamics which might more closely follow those in an economy where investment in organization capital is modeled explicitly, an extension we plan to explore. Thus, the stock of organization capital in firm $i$ evolves according to

$$
d \mathcal{O}_{i t}=\left(g\left(\varepsilon_{i, t}\right)-\delta\right) \mathcal{O}_{i, t} d t
$$

where $g$ is the efficiency specific growth rate of organization capital. The shareholders of the firm do not wholly own the organization capital, instead it is partially owned by the managers and workers of the firm. If they leave, these workers can transfer part of the accumulated knowledge and existing organization structure to a newly created firm.

Over time, new technologies which improve the frontier efficiency of organization capital emerge. In the spirit of the "blueprints" in Atkeson and Kehoe (2005), only new firms created at time $t$ can adopt the frontier efficiency. New firms begin with efficiency $\varepsilon_{i t}=x_{t}$ where the frontier efficiency $x$ evolves according to

$$
d x_{t}=-\kappa_{x} x_{t} d t+\sigma_{x} d Z_{t}^{x}
$$

Subsequent to formation, new firms' organization capital evolves according to (4).

The creation of a new firm requires $K$ units of physical capital and may also attract organization capital away from existing firms. At firms in which the efficiency of organization capital lags behind the frontier, the owners of the organization capital have the incentive to leave for a newly created firm. These workers can capture part of the rents from deploying the organization capital in the new firm.

Because part of the accumulated knowledge was tied to the old organization technology of the existing firm, in order to deploy the organization capital at a new firm and at the frontier efficiency, a restructuring cost must be paid. This cost can be interpreted as an interruption of the production process due to the necessary retraining of workers and adjustment of the organization structure to the new technology, or as costs from the obsolescence of existing organization capital in the new technology. A new firm that wants to deploy a level of organization capital 
$\mathcal{O}$ needs to pay a cost equal to

$$
C(\theta, \mathcal{O})=c \theta \mathcal{O}
$$

Firms cannot produce with organization capital alone but require physical capital to do so. Physical capital may be created using a linear investment technology or may be purchased from existing firms. As a result, the price of capital in this economy is equal to its marginal product.

\subsection{Stochastic Discount Factor}

We have described the stochastic environment of our economy under the physical measure. In order to value organization capital and firms in our economy, we will change measure. This will allow us to price risk while still discounting at the risk free rate. The change in measure will be implicitly defined by a stochastic discount factor which places more weight on states with high marginal values.

Markets are complete and there exist no arbitrage opportunities. These two assumptions imply that there exists a unique stochastic discount factor in the economy, $(\pi)$, which can be used to price any cashflow stream. In this economy, the stochastic discount factor follows

$$
d \pi_{t}=-r \pi_{t} d t-\lambda_{\theta} d Z_{t}-\lambda_{x} d Z_{t}^{x}
$$

The parameters $\lambda_{\theta}$ and $\lambda_{x}$ in Equation (8) determine the price of risk for the aggregate technological shock $\theta$ and the level of the frontier organization efficiency $x$, respectively. We assume that $\lambda_{x}<0$, or in other words that improvements in the frontier technology imply that the marginal value of resources is high. Because adopting the frontier technology requires resources, whereas the output of existing firms is not affected, aggregate consumption should be lower in these states, resulting in higher marginal utility ${ }^{9}$ Finally, the interest rate is constant and equal to $r$.

\footnotetext{
${ }^{9}$ See Papanikolaou (2008) for a general equilibrium treatment of investment specific shocks which also require expenditures without affecting current output and thus raise the marginal value of resources.
} 
As an aside, Equation (8) also implicitly defines the risk neutral equivalent probability measure as

$$
\frac{d \mathcal{Q}}{d \mathcal{P}}=\exp \left(-\lambda_{x} Z_{t}^{x}-\lambda_{\theta} Z_{t}-\frac{1}{2} \lambda_{x}^{2} t-\frac{1}{2} \lambda_{\theta}^{2} t\right)
$$

The dynamics of $\theta$ and $x$ under the EMM $\mathcal{Q}$ are given by

$$
d \theta_{t}=\left(\mu_{\theta}-\sigma_{\theta} \lambda_{\theta}\right) \theta_{t} d t+\sigma_{\theta} \theta_{t} d \tilde{Z}_{t}
$$

and

$$
d x_{t}=-\kappa_{x}\left(x_{t}-\bar{x}\right) d t+\sigma_{x} d \tilde{Z}_{t}^{x},
$$

where $\bar{x} \equiv \frac{-\sigma_{x} \lambda_{x}}{\kappa_{x}}$ and $d \tilde{Z}_{t}=d Z_{t}+\lambda_{\theta} d t$ and $d \tilde{Z}_{t}^{x}=d Z_{t}^{x}+\lambda_{x} d t$ are Brownian motions under $\mathcal{Q}$.

Finally, the price of a cashflow stream $X_{t}$, can be computed by discounting these cashflows at the risk free rate under the new measure $\mathcal{Q}$ where probabilities have been adjusted as follows:

$$
\begin{aligned}
V\left(X_{t}\right) & =E_{t} \int_{t}^{\infty} \frac{\pi_{s}}{\pi_{t}} X_{s} d s \\
& =E_{t}^{\mathcal{Q}} \int_{t}^{\infty} e^{-r(s-t)} X_{s} d s .
\end{aligned}
$$

\subsection{Firm Value}

Consider a firm $i$ that has accumulated organization capital $\mathcal{O}_{i}$ and currently has a level of efficiency $\varepsilon_{i t}$. First, we will value the organization capital in this firm. Next, we will show how this value is split between shareholders, and management or labor. Finally, we will compute the total value of the firm, from the shareholder's perspective, and show that firms with high organization capital earn higher expected returns in equilibrium. 


\subsubsection{Value of Organization Capital}

First, we will value the organization capital of this firm. The value of the organization capital will equal the expectation of the discounted future cashflows while the organization capital stays with this firm under the measure $\mathcal{Q}$, plus its outside value in the event of reallocation. This value will depend on the common neutral technology shock $\theta$, the firm's stock of organization capital $\mathcal{O}$, its organization efficiency $\varepsilon_{i}$, and the frontier organization capital technology $x$ as follows:

$$
V_{\mathcal{O}}\left(\theta_{t}, \mathcal{O}_{i, t}, \varepsilon_{i, t}, x_{t}\right)=E_{t}^{\mathcal{Q}} \int_{t}^{\tau} e^{-r(s-t)} \theta_{s} \mathcal{O}_{i, s} \exp \left(\varepsilon_{i, s}\right) d s+E_{t}^{\mathcal{Q}} e^{-r(\tau-t)} \bar{V}_{\mathcal{O}, \tau}
$$

Time $\tau$ is the random stopping time at which it is optimal to reallocate the organization capital to a new firm, the first term gives the cashflows generated by the firm's organization capital, and the second term, $\bar{V}_{\mathcal{O}, \tau}$, denotes organization capital's outside value. Managers and workers always have the option to depart for a new firm. Moreover, because the supply of physical capital is perfectly elastic, they can extract all of the rents from organization capital at the time the firm is created. Organization capital's outside option would thus equal the total value of organization capital when the firm's organization efficiency is equal to that of the frontier technology, or,

$$
\bar{V}_{\mathcal{O}}=V_{\mathcal{O}}\left(\theta_{t}, \mathcal{O}_{i, t}, x_{t}, x_{t}\right)
$$

Note that this means, from shareholders' perspective, new firms will always be zero NPV. The following proposition describes how we can compute the value of organization capital in our economy.

Proposition 1. The value of organization capital deployed in firm $i$ equals

$$
V_{\mathcal{O}}=\theta_{t} \mathcal{O}_{i, t} v\left(\varepsilon_{i, t}, x_{t}\right)
$$

where in the continuation region $v(\varepsilon, x)$ is the solution to

$$
0=\exp (\varepsilon)-\rho(\varepsilon) v-\kappa_{\varepsilon} \varepsilon v_{\varepsilon}+\frac{1}{2} \sigma_{\varepsilon}^{2} v_{\varepsilon \varepsilon}-\kappa_{x}(x-\bar{x}) v_{x}+\frac{1}{2} \sigma_{x}^{2} v_{x x}
$$


The continuation region is defined by $\varepsilon_{i, t} \geq \varepsilon^{*}\left(x_{t}\right)$, where $\varepsilon^{*}(x)$ solves

$$
v\left(\varepsilon^{*}(x), x\right)=v(x, x)-c \equiv \bar{v}(x)
$$

Proof: The value of organization capital deployed in firm $i$ equals

$$
\begin{aligned}
V_{\mathcal{O}} & =E_{t}^{\mathcal{Q}} \int_{t}^{\tau} e^{-r(s-t)} \theta_{s} \mathcal{O}_{i, s} \exp \left(\varepsilon_{i, s}\right) d s+E_{t}^{\mathcal{Q}} e^{-r(\tau-t)} \bar{V}_{\mathcal{O}, \tau} \\
& =\theta_{t} \mathcal{O}_{i, t} E_{t}^{\mathcal{Q}} \int_{t}^{\tau} e^{-\int_{t}^{s} \rho\left(\varepsilon_{i, u}\right) d u} \exp \left(\varepsilon_{i, s}\right) d s+E_{t}^{\mathcal{Q}} e^{-r(\tau-t)} \bar{V}_{\mathcal{O}, \tau}
\end{aligned}
$$

where

$$
\rho(\varepsilon)=r+\lambda_{\theta} \sigma_{\theta}-\mu_{\theta}-g(\varepsilon)+\delta .
$$

The first equality holds by the law of iterated expectations and the definition of $\rho$ follows from our description of the stochastic processes for $\theta$ and $\mathcal{O}$. We guess that the value of organization capital can be written as:

$$
V_{\mathcal{O}}=\theta_{t} \mathcal{O}_{i, t} v\left(\varepsilon_{i, t}, x_{t}\right)
$$

Given that the supply of capital is perfectly elastic, the owners of organization capital will extract all of the rents it accrues in newly created firms. Thus, we know that at time $t$ organization capital's outside option is given by the total value of the organization capital in the new firm, where it will operate at the frontier efficiency, less the adjustment cost necessary to retool the old organization capital. This outside option can be written as:

$$
\theta_{t} \mathcal{O}_{i, t} v\left(x_{t}, x_{t}\right)-C\left(\theta_{t}, \mathcal{O}_{i, t}\right)
$$

Thus, comparing the inside and outside option, we see that organization capital will only be reallocated to a new firm if

$$
v\left(\varepsilon_{i, t}, x_{t}\right)<v\left(x_{t}, x_{t}\right)-c
$$


In the continuation region, the value of organization capital including current cashflow is a martingale, and thus $v$ is the solution to (15), which verifies our guess. Because $v\left(\varepsilon_{i, t}, x_{t}\right)$ is monotonically increasing in $\varepsilon$, continuation will be efficient as long as $\varepsilon_{i, t} \geq \varepsilon^{*}\left(x_{t}\right)$. At the threshold $\varepsilon^{*}\left(x_{t}\right)$ defined by (16), the value of organization capital inside the firm equals exactly its value in a new firm minus installation costs, at which point the owners of organization capital are indifferent between continuation and reallocation. QED

\subsubsection{Division of Value between Shareholders and Labor}

At time $t$, organization capital's outside option $\bar{V}_{\mathcal{O}, \tau}$ is given by

$$
\theta_{t} \mathcal{O}_{i, t} v\left(x_{t}, x_{t}\right)-C\left(\theta_{t}, \mathcal{O}_{i, t}\right)=\theta_{t} \mathcal{O}_{i, t} \bar{v}\left(x_{i, t}\right)
$$

If the firm pays the owners of organization capital a flow payment of $w_{t} d t$ as long as it stays within the firm, the present value of these payments plus the organization capital's outside option will equal

$$
W_{t}=E_{t}^{\mathcal{Q}} \int_{t}^{\tau} e^{-r(s-t)} w_{s} d s+E_{t}^{\mathcal{Q}} e^{-r(\tau-t)} \bar{V}_{\mathcal{O}, \tau}
$$

In order for the organization capital to remain with the firm, its owners must receive, in present value terms, at least the value of their outside option. In addition, we assume that the firm cannot commit to pay workers more than their outside option 10 This means, that in every state of the world, the present value of all future payments to workers must equal their outside option,

$$
W_{t}=\theta_{t} \mathcal{O}_{i, t} \bar{v}\left(x_{i, t}\right)
$$

\footnotetext{
${ }^{10}$ The assumption that workers receive no more than the present value of their outside option simplifies our analysis. Given that we effectively assume that shareholders and laborers are diversified, i.e. their marginal utility does not depend on $\varepsilon_{i}$, allowing for firm commitment would yield an indeterminacy in terms of payment plans. Lustig, Syverson and Van Nieuwerburgh (2008) consider risk averse managers and provide an interesting analysis of the division of the surplus over and above workers' outside option following Thomas and Worall (1988).
} 
We will use these two properties of the payments to organization capital, described in Equations (17) and (18), to derive the process for the instantaneous cashflow to labor, $w_{t} d t$. Intuitively, the requirement that the manager's continuation value equals his outside option in every state of the world pins down $W_{t}$ and $W_{t+d t}$. The firm will then compensate the manager in such a way as to satisfy this and to make $W_{t}=w_{t}+e^{-r d t} E_{t}^{\mathcal{Q}} W_{t+d t}$ hold always. The flow payments to organization capital are described in the following proposition:

Proposition 2. The owners of organization capital receive a flow payment $w_{t} d t$ every period, given by

$$
w_{t}=\left(\rho\left(\varepsilon_{i, t}\right)+\sigma_{\theta} \lambda_{\theta}+\kappa_{x}\left(x_{t}-\bar{x}\right) \frac{\bar{v}_{x}}{\bar{v}}-\frac{1}{2} \sigma_{x}^{2} \frac{\bar{v}_{x x}}{\bar{v}}\right) W_{t},
$$

where $\bar{v}(x)$ is defined in Equation (16).

Proof: Lack of commitment on both sides implies that $W_{t}=\bar{V}_{\mathcal{O}}=\theta_{t} \mathcal{O}_{i, t} \bar{v}\left(x_{i, t}\right)$ must always hold. Under $\mathcal{P}$, an application of Ito's Lemma implies that organization capital's outside option for $t<\tau$ evolves according to:

$$
\begin{aligned}
d \bar{V}_{\mathcal{O}}= & \left(\mu_{\theta}+g\left(\varepsilon_{i, t}\right)-\delta\right) \bar{V}_{\mathcal{O}} d t+\sigma_{\theta} \bar{V}_{\mathcal{O}} d Z_{t}-\kappa_{x} x_{t} \bar{V}_{\mathcal{O}} \frac{\bar{v}_{x}}{\bar{v}} d t+ \\
& +\bar{V}_{\mathcal{O}} \frac{\bar{v}_{x}}{\bar{v}} \sigma_{x} d Z_{t}^{x}+\frac{1}{2} \sigma_{x}^{2} \frac{\bar{v}_{x x}}{\bar{v}} \bar{V}_{\mathcal{O}} d t
\end{aligned}
$$

In the event where separation or restructuring occurs, organization capital has exercised its option to leave. At this point, labor can extract no more rents from the old firm and thus receives no more payments. The martingale representation theorem and Equation (17) imply that under $\mathcal{Q}$, and as long as $t<\tau$,

$$
d W_{t}=\left(r W_{t}-w_{t}\right) d t+b_{x} d \tilde{Z}_{t}^{x}+b_{i} d Z_{t}^{i}+b_{\theta} d \tilde{Z}_{t}
$$

Given the change of measure defined by Equations (10) and (11), under $\mathcal{P}$ we have 
that

$$
d W_{t}=\left(r W_{t}-w_{t}\right) d t+b_{x}\left(d Z_{t}^{x}+\lambda_{x} d t\right)+b_{i} d Z_{t}^{i}+b_{\theta}\left(d Z_{t}^{\theta}+\lambda_{\theta} d t\right)
$$

The shareholders will choose a flow payment $w_{t} d t$ and sensitivities $b_{x}, b_{i}$ and $b_{\theta}$, to compensate organization capital to make sure that $W_{t}=\bar{V}_{\mathcal{O}}$ holds in every state of the world. This boils down to ensuring that $d W_{t}=d \bar{V}_{\mathcal{O}}$ for all $\mathrm{t}$ and realizations of the Brownian shocks $d Z_{t}^{\theta}, d Z_{t}^{x}$ and $d Z_{t}^{\varepsilon i}$. Matching coefficients yields:

$$
\begin{aligned}
b_{\theta} & =\sigma_{\theta} W_{t} \\
b_{i} & =0 \\
b_{x} & =\sigma_{x} \frac{\bar{v}_{x}}{\bar{v}} \bar{V}_{\mathcal{O}} \\
r W_{t}-w_{t}+b_{x} \lambda_{x}+b_{\theta} \lambda_{\theta} & =\left(\mu_{\theta}+g\left(\varepsilon_{i, t}\right)-\delta\right) \bar{V}_{\mathcal{O}}-\kappa_{x} x_{t} \frac{\bar{v}_{x}}{\bar{v}} \bar{V}_{\mathcal{O}}+\frac{1}{2} \sigma_{x}^{2} \frac{\bar{v}_{x x}}{\bar{v}} \bar{V}_{\mathcal{O}}
\end{aligned}
$$

Finally, combining these four equations yields Equation (19). QED

\subsubsection{Shareholder value of the firm}

In this section we derive the value of the entire firm from the shareholders' perspective. Shareholders have full ownership of the physical capital stock, but also derive some rents from organization capital.

The value of the firm's physical capital equals the present value of all cashflows generated by it:

$$
V_{\mathcal{K}}=E_{t}^{\mathcal{Q}} \int_{t}^{\infty} e^{-r(s-t)} \theta_{s} K=\frac{1}{r+\lambda_{\theta} \sigma_{\theta}-\mu_{\theta}} \theta_{t} K \equiv q \theta_{t} K
$$

In addition to $V_{\mathcal{K}}$, shareholders also capture the difference between the value of the organization capital in the firm and its outside option. Therefore, the total value of the firm, equals

$$
V_{\text {firm }}=q \theta_{t} K+\theta_{t} \mathcal{O}_{i, t}\left(v\left(\varepsilon_{i, t}, x_{t}\right)-\bar{v}\left(x_{t}\right)\right)
$$

The following proposition describes the properties of the cross section of expected returns, and shows that in this economy variation in expected returns is driven by 
variation in organization capital.

Proposition 3. Expected returns for firm $i$ will be equal to

$$
r+\lambda_{\theta} \sigma_{\theta}+\lambda_{x} \sigma_{x} \lambda\left(\varepsilon_{i, t}, x_{t}\right) \frac{\frac{\mathcal{O}_{t}}{K}\left(v\left(\varepsilon_{t}, x_{t}\right)-\bar{v}\left(x_{t}\right)\right)}{q+\frac{\mathcal{O}_{t}}{K}\left(v\left(\varepsilon_{t}, x_{t}\right)-\bar{v}\left(x_{t}\right)\right)}
$$

where

$$
\lambda(\varepsilon, x)=\frac{v_{x}(\varepsilon, x)-\bar{v}_{x}(x)}{v(\varepsilon, x)-\bar{v}(x)}
$$

Proof An asset's expected return in excess of the risk free rate is equal to the difference of its drift between the $\mathcal{P}$ and $\mathcal{Q}$ measures. Thus, applying Ito's lemma to Equation (21) and computing the difference in drift terms under $\mathcal{P}$ and $\mathcal{Q}$ yields

$$
\begin{aligned}
\mu_{i} V_{\text {firm }} d t-r V_{\text {firm }} d t & =\lambda_{\theta} \sigma_{\theta} \theta_{t} \frac{\partial V_{\text {firm }}}{\partial \theta} d t+\lambda_{x} \sigma_{x} \frac{\partial V_{\text {firm }}}{\partial x} d t \\
& =\lambda_{\theta} \sigma_{\theta} V_{\text {firm }} d t+\lambda_{x} \sigma_{x}\left(\theta_{t} \mathcal{O}_{t}\left(v_{x}\left(\varepsilon_{t}, x_{t}\right)-\bar{v}_{x}\left(x_{t}\right)\right)\right) d t \\
& =\lambda_{\theta} \sigma_{\theta} V_{\text {firm }} d t+\lambda_{x} \sigma_{x} \frac{\frac{\mathcal{O}_{t}}{K}\left(v_{x}\left(\varepsilon_{t}, x_{t}\right)-\bar{v}_{x}\left(x_{t}\right)\right)}{q+\frac{\mathcal{O}_{t}}{K}\left(v\left(\varepsilon_{t}, x_{t}\right)-\bar{v}\left(x_{t}\right)\right)} V_{\text {firm }} d t
\end{aligned}
$$

QED.

Risk premia are determined by factor loadings times the price of risk. All firms have the same exposure to the aggregate productivity shock $(\theta)$. Therefore, any difference in risk premia across firms arises due to differential sensitivity to the frontier shock $(x)$. The value of the rents that shareholders can extract from organization capital falls with $x$, since the frontier shock increases organization capital's outside option. Thus, $\lambda(\varepsilon, x)<0$. As long as high $x$ states are also high marginal valuation states, $\left(\lambda_{x}<0\right)$, this implies that firm's risk premia will be an increasing function of $\mathcal{O} / K$

\subsection{Numerical Solution and Simulation}

We solve the model numerically, where the computational details are described in the Appendix. Our choice of parameter values is shown in Table 7 . While we aim 
to provide a more careful calibration in a future draft, the current parameterization of the model allows us to illustrate the main features of the model's solution. The parameter $a$ governs the efficiency specific growth rate of organization capital, where $g\left(\varepsilon_{i t}\right)=a \varepsilon_{i t}$ Our assumptions about the mean reverting parameters $\kappa_{\varepsilon}$ and $\kappa_{x}$ imply that firm-specific productivity shocks have a half life of 3.1 years, whereas the frontier technology shock has a half-life of 6.6 years.

Figure (2) describes the main inputs into the solution to our model of organization capital. The top left panel graphs values of $v\left(\varepsilon_{t}, x_{t}\right)$ and shows that this value is increasing in both firm specific efficiency and the frontier efficiency. This value is the value of the cashflows generated by organization capital while it remains in the firm plus the value of organization capital's outside option. The top right panel of figure (2) graphs the value of organization capital's outside option as a function of the frontier organization efficiency and shows that this outside option is increasing. The bottom left panel graphs the lowest firm specific organization efficiency for which organization capital remains with the firm and this cutoff also increases with improvements to the frontier efficiency. Finally, the bottom right panel of figure (2) graphs $v\left(\varepsilon_{t}, x_{t}\right)-\bar{v}(x)$ and shows that while this value is increasing in $\varepsilon$ it is decreasing in $x$ due to the subtraction of the outside option. This illustrates why the value to shareholders of firms with large stocks of organization capital is sensitive to shocks to the frontier technology. The payments to organization capital depend on outside options to work at this frontier efficiency and this decreases the value to shareholders.

To compare our model to the data described in Section 2, we simulate the model at monthly intervals and compound monthly returns to form annual returns. We then repeat the procedure described in Section 2 and sort firms into 5 portfolios based on their ratio of organization capital to physical capital $(K)$. We present the results in Table 8. The cross section of returns replicates the pattern found in the data, and comes close to matching the spread in expected returns between the high and low organization capital portfolios. 


\section{Conclusion}

In this paper we have argued that organization capital has risk characteristics distinct from those of physical capital, and that the risk inherent in this type of specific, intangible, capital requires significant risk premia. We document a sizable return premium for firms with substantial stocks of organization capital, and show that the excess return to a portfolio which is long high organization capital firms and short low organization capital firms cannot be explained by standard risk factors. The model economy we construct attributes the risk of organization capital to the fact that it is highly firm specific and cannot wholly be owned by shareholders. 


\section{References}

Atkeson, A. and Kehoe, P. J. (2005). Modeling and measuring organization capital, Journal of Political Economy 113(5): 1026-1053.

Black, S. E. and Lynch, L. M. (2005). Measuring organizational capital in the new economy, IZA Discussion Papers 1524, Institute for the Study of Labor (IZA).

Blair, M. M. and Wallman, S. M. H. (2001). Unseen Wealth, Brookings Institution Press.

Caballero, R. J. (2007). Specificity and the Macroeconomics of Restructuring, MIT Press.

Caballero, R. J. and Hammour, M. L. (2001). Advances in Macroeconomic Theory, Palgrave, chapter Institutions, Restructuring, and Macroeconomic Performance.

Caballero, R. J. and Hammour, M. L. (2005). The cost of recessions revisited: A reverse-liquidationist view, Review of Economic Studies 72(2): 313-341.

Chowdhry, B. and Garmaise, M. (2003). Organization capital and intrafirm communication, University of California at Los Angeles, Anderson Graduate School of Management 1108, Anderson Graduate School of Management, UCLA.

Davis, S. J., Haltiwanger, J. and Schuh, S. (1996). Job Creation and Destruction, MIT Press.

Eisfeldt, A. L. and Rampini, A. A. (2006). Capital reallocation and liquidity, Journal of Monetary Economics 53(3): 369-399.

Eisfeldt, A. L. and Rampini, A. A. (2007). Financing shortfalls and the value of aggregate liquidity, Working paper, Northwestern University.

Ericson, R. and Pakes, A. (1995). Markov-perfect industry dynamics: A framework for empirical work, The Review of Economic Studies 62(1): 53-82. 
Fama, E. F. and French, K. R. (1993). Common risk factors in the returns on stocks and bonds, Journal of Financial Economics 33(1): 3-56.

Fama, E. F. and French, K. R. (1997). Industry costs of equity, Journal of Financial Economics 43(2): 153-193.

Foster, L., Haltiwanger, J. and Krizan, C. (2001). New Developments in Productivity Analysis, University of Chicago Press, chapter Aggregate Productivity Growth: Lessons from Microeconomic Evidence.

Hall, R. E. (2000a). E-capital: The link between the stock market and the labor market in the 1990s, Brookings Papers on Economic Activity 31(2000-2): 73118.

Hall, R. E. (2000b). Reorganization, Carnegie-Rochester Conference Series on Public Policy 52(1): 1-22.

Hall, R. E. (2001). The stock market and capital accumulation, American Economic Review 91(5): 1185-1202.

Hansen, L. P., Heaton, J. C. and Li, N. (2004). Intangible risk?, Working paper.

Hodrick, R. J. and Prescott, E. C. (1997). Postwar u.s. business cycles: An empirical investigation, Journal of Money, Credit and Banking 29(1): 1-16.

Jovanovic, B. and Rousseau, P. L. (2001). Vintage organization capital, NBER Working Papers 8166, National Bureau of Economic Research, Inc.

Jovanovic, B. and Rousseau, P. L. (2008). Specific capital and technological variety, NBER Working Papers 13998, National Bureau of Economic Research, Inc.

Lev, B. (2001). Intangibles: Management, Measurement, and Reporting, Brookings Institution Press.

Lev, B. and Radhakrishnan, S. (2004). The valuation of organization capital, Working papers, NYU Stern School of Business. 
Lustig, H., Syverson, C. and Nieuwerburgh, S. V. (2008). IT, corporate payouts, and the growing inequality in managerial compensation, Finance working papers, NYU Stern.

Maksimovic, V. and Phillips, G. (2001). The market for corporate assets: Who engages in mergers and asset sales and are there efficiency gains?, Journal of Finance 56(6): 2019-2065.

Papanikolaou, D. (2008). Investment-specific technological change and asset prices, Working paper, Northwestern University.

Prescott, E. C. and Visscher, M. (1980). Organization capital, Journal of Political Economy 88(3): 446-61.

Rosen, S. (1972). Learning by experience as joint production, The Quarterly Journal of Economics 86(3): 366-82.

Sliker, B. K. (2007). R\&D satellite account methodologies: R\&D capital stocks and net rates of return, RED satellite account background paper, Bureau of Economic Analysis/National Science Foundation. 


\section{Tables}

Table 1: Summary Statistics: 5 portfolios sorted on OC/A

\begin{tabular}{lcccccc}
\hline \hline Portfolio & & Lo & 2 & 3 & 4 & Hi \\
\cline { 1 - 4 } \cline { 5 - 7 } MKCAP (\% of CRSP total ) & & $16.2 \%$ & $15.3 \%$ & $17.1 \%$ & $20.3 \%$ & $11.2 \%$ \\
Organization Capital to Book Assets & & 0.174 & 0.456 & 0.749 & 1.111 & 1.844 \\
Physical Capital to Book Assets & & 0.298 & 0.244 & 0.230 & 0.227 & 0.206 \\
Book-to-Market Equity (portfolio) & & 0.646 & 0.569 & 0.521 & 0.492 & 0.498 \\
Book-to-Market Equity & & 0.719 & 0.745 & 0.762 & 0.772 & 0.798 \\
Debt-to-Assets & & 0.251 & 0.213 & 0.196 & 0.184 & 0.167 \\
Capital-to-Labor (log) & & 3.268 & 3.015 & 2.871 & 2.747 & 2.428 \\
Investment to Capital (organization) & 0.488 & 0.458 & 0.394 & 0.346 & 0.305 \\
Investment to Capital (physical) & & 0.231 & 0.238 & 0.226 & 0.221 & 0.221 \\
\hline \hline
\end{tabular}

Table 1 shows time-series averages of characteristics of the 5 portfolios sorted on organization capital over Book Assets (Compustat item 6) relative to the industry. We use the 17 industry classification of Fama and French (1997). Organization capital is defined as $O_{i, t}=(1-\delta) O_{i, t-1}+S G A_{i, t}$, where $S G A$ is Selling, General and Administrative Expenses (Compustat item 189), following Lev and Radhakrishnan (2004). We chose $\delta=0.2$. In the portfolio sorts, we only include firms where $O_{i, t}>0$. We use medians as measures of portfolio characteristics except when we measure the book to market ratio of the portfolio, in which case we value-weight by market capitalization, and the first row which shows t each portfolio's market capitalization as a fraction of the total. For characteristics we use physical capital (item 8), Book Equity (item 60), Debt (item 9+item 34), and Labor (item 29). The sample period is January 1970 to December 2006. 
Table 2: Determinants of investment in Organizational Capital

\begin{tabular}{lccccc}
\hline \hline$i_{t}^{o c}$ & $(\mathrm{~A})$ & $(\mathrm{B})$ & $(\mathrm{C})$ & $(\mathrm{D})$ & $(\mathrm{E})$ \\
\hline$\Delta y_{t-1}$ & 0.037 & 0.036 & 0.036 & 0.076 & 0.068 \\
& $(13.96)$ & $(13.70)$ & $(13.39)$ & $(18.63)$ & $(18.12)$ \\
$Q_{t-1}$ & 0.018 & 0.018 & 0.019 & 0.041 & 0.042 \\
& $(12.56)$ & $(12.49)$ & $(12.30)$ & $(12.96)$ & $(12.96)$ \\
$C F_{t-1} / A_{t-1}$ & 0.185 & 0.183 & 0.175 & 0.164 & 0.149 \\
& $(32.63)$ & $(32.11)$ & $(30.41)$ & $(15.13)$ & $(14.47)$ \\
$E_{t-1} / A_{t-1}$ & 0.015 & 0.012 & 0.013 & 0.080 & 0.042 \\
& $(4.79)$ & $(3.91)$ & $(4.06)$ & $(3.97)$ & $(3.17)$ \\
$O_{t-1} / A_{t-1}$ & -0.003 & -0.006 & -0.006 & -0.099 & -0.078 \\
& $(-4.32)$ & $(-9.84)$ & $(-8.93)$ & $(-22.33)$ & $(-20.89)$ \\
$i_{t-1}^{o c}$ & 0.478 & 0.474 & 0.474 & & \\
& $(151.87)$ & $(149.66)$ & $(146.77)$ & & \\
\hline Industry Effects & $\mathrm{N}$ & $\mathrm{Y}$ & $\mathrm{Y}$ & $\mathrm{N}$ & $\mathrm{N}$ \\
Time Effects & $\mathrm{N}$ & $\mathrm{N}$ & $\mathrm{Y}$ & $\mathrm{N}$ & $\mathrm{Y}$ \\
Firm Effects & $\mathrm{N}$ & $\mathrm{N}$ & $\mathrm{N}$ & $\mathrm{Y}$ & $\mathrm{Y}$ \\
\hline$R^{2}$ & 0.643 & 0.646 & 0.649 & 0.245 & 0.329 \\
\hline \hline
\end{tabular}

Table 2 shows estimates of a regression of investment rates on organizational capital on firm characteristics. The variables are defined as follows O: Organizational Capital, defined as $O_{i, t}=$ $(1-\delta) O_{i, t-1}+S G A_{i, t}$, where $S G A$ is Selling, General and Administrative Expenses (Compustat item 189), $i_{t}^{o c}=S G A_{t} / O_{t-1}, \mathrm{y}: \log$ sales (Compustat item 12) E: Book Equity (Compustat item 60), A: Book Assets (Compustat item 6), CF: Cashflows (Compustat item $14+$ item 18), Q: December market capitalization from CRSP over Book Assets plus Organizational Capital. We drop observations where $i^{o c}>2$ and $C F / A>1$, leaving us with 96,465 firm-year observations. The sample period is January 1970 to December 2006. For the industry fixed effects we use the 17 industry classification of Fama and French (1997). Standard errors are robust to heteroscedasticity and clustered at the firm level. 
Figure 1: High minus Low OC stock returns versus Turnover Rate of PPE

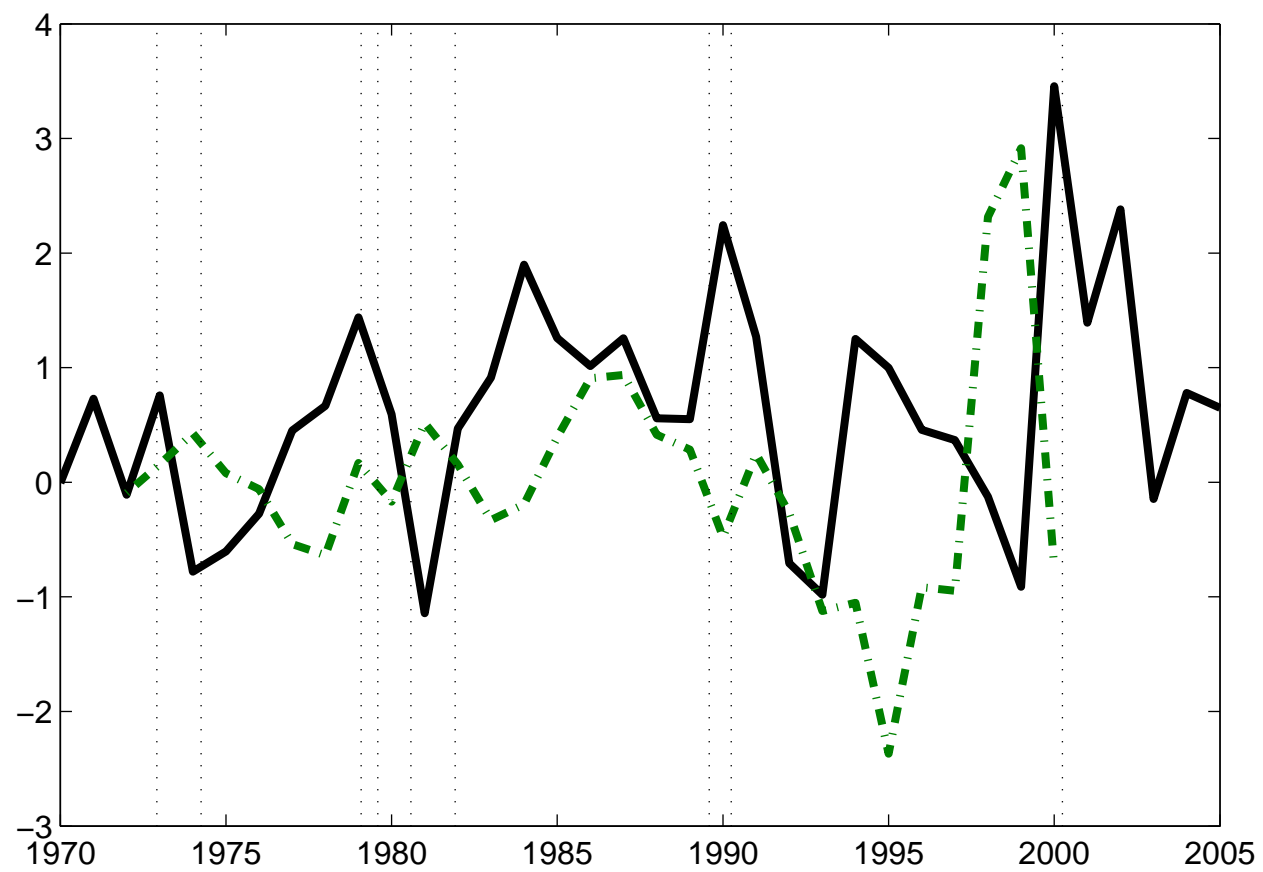

Figure 1 plots the returns of the high minus low organization capital portfolios versus the turnover rate of Property Plant and Equipment (PPE), from Eisfeldt and Rampini (2006). The turnover is defined as aggregate sales of PPE in Compustat data relative to aggregate PPE. The turnover rate is filtered using the Hodrick-Prescott (1997) filter with a weight of 100. The correlation between the two series is $-29 \%$. Dotted vertical lines plot NBER recession dates. 
Table 3: Asset Pricing: 5 portfolios sorted on OC/A

\begin{tabular}{|c|c|c|c|c|c|c|}
\hline Portfolio & Lo & 2 & 3 & 4 & $\mathrm{Hi}$ & Hi-Lo \\
\hline \multirow[t]{2}{*}{$E\left(R_{i}\right)-r_{f}(\%)$} & 4.41 & 5.99 & 6.86 & 8.22 & 9.07 & 4.66 \\
\hline & $(2.91)$ & $(3.10)$ & $(2.85)$ & $(2.58)$ & $(2.65)$ & $(1.37)$ \\
\hline$\sigma(\%)$ & 17.43 & 18.62 & 17.10 & 15.50 & 15.88 & 8.20 \\
\hline \multirow[t]{2}{*}{$\beta_{M K T}$} & 1.08 & 1.13 & 1.06 & 0.95 & 0.95 & -0.13 \\
\hline & $(0.02)$ & $(0.02)$ & $(0.01)$ & $(0.02)$ & $(0.03)$ & $(0.04)$ \\
\hline \multirow[t]{2}{*}{$\alpha(\%)$} & -2.54 & -1.29 & 0.03 & 2.09 & 2.96 & 5.50 \\
\hline & $(0.76)$ & $(0.99)$ & $(0.71)$ & $(0.74)$ & $(0.94)$ & $(1.36)$ \\
\hline$R^{2}(\%)$ & 93.94 & 90.03 & 94.32 & 92.23 & 87.30 & 6.29 \\
\hline \multirow[t]{2}{*}{$\beta_{M K T}$} & 1.08 & 1.08 & 1.04 & 0.97 & 0.97 & -0.11 \\
\hline & $(0.02)$ & $(0.03)$ & $(0.02)$ & $(0.02)$ & $(0.02)$ & $(0.03)$ \\
\hline \multirow[t]{2}{*}{$\beta_{S M B}$} & 0.06 & 0.10 & -0.01 & -0.12 & -0.08 & -0.14 \\
\hline & $(0.03)$ & $(0.04)$ & $(0.02)$ & $(0.02)$ & $(0.03)$ & $(0.04)$ \\
\hline \multirow[t]{2}{*}{$\beta_{H M L}$} & 0.04 & -0.10 & -0.07 & -0.01 & 0.02 & -0.02 \\
\hline & $(0.04)$ & $(0.05)$ & $(0.03)$ & $(0.03)$ & $(0.05)$ & $(0.07)$ \\
\hline \multirow[t]{2}{*}{$\alpha(\%)$} & -2.94 & -0.69 & 0.59 & 2.34 & 2.89 & 5.82 \\
\hline & $(0.63)$ & $(0.78)$ & $(0.59)$ & $(0.61)$ & $(0.80)$ & $(1.10)$ \\
\hline$R^{2}(\%)$ & 94.10 & 90.77 & 94.49 & 92.98 & 87.70 & 9.81 \\
\hline
\end{tabular}

Table 3 shows asset pricing tests for 5 portfolios sorted on organization capital over assets (Compustat item 6) relative to the industry. We classify firms into 17 industries, according to Fama and French (1997). The portfolios SMB and HML refer to a portfolio long small and short large stocks and a portfolio long value (high $\mathrm{BE} / \mathrm{ME}$ ) and short growth (low BE/ME) stocks, as defined in FF1993. Organization capital is defined as $O_{i, t}=(1-\delta) O_{i, t-1}+S G A_{i, t}$, where $S G A$ is Selling, General and Administrative Expenses (Compustat item 189), following Lev and Radhakrishnan (2004). We chose $\delta=0.2$. In the portfolio sorts, we only include firms where $O_{i, t}>0$. The sample period is January 1970 to December 2006. Standard errors (reported in parenthesis) are computed using the Newey-West estimator allowing for 1 lag of serial correlation in returns. All numbers are annualized by multiplying by 12 . 
Table 4: Portfolio transition probabilities: 5 portfolios sorted on OC/A

\begin{tabular}{rrrrrrr}
\hline \hline & \multicolumn{5}{c}{ Sort(t-1) } \\
\cline { 2 - 7 } & & Lo & 2 & 3 & 4 & Hi \\
\cline { 3 - 7 } & Lo & $72.1 \%$ & $7.3 \%$ & $0.8 \%$ & $0.4 \%$ & $0.2 \%$ \\
Sort(t) & 2 & $23.8 \%$ & $59.5 \%$ & $10.3 \%$ & $1.5 \%$ & $0.5 \%$ \\
& 3 & $2.9 \%$ & $27.8 \%$ & $60.5 \%$ & $11.3 \%$ & $1.4 \%$ \\
& 4 & $0.9 \%$ & $4.3 \%$ & $25.2 \%$ & $67.3 \%$ & $10.1 \%$ \\
& Hi & $0.3 \%$ & $1.1 \%$ & $3.1 \%$ & $19.6 \%$ & $87.9 \%$ \\
\hline \hline
\end{tabular}

Table 4 plots the transition probabilities across portfolio quintiles. Stocks are sorted into portfolios based on Organization Capital over Book Assets (Compustat item 6) relative to the industry. We use the 17 industry classification of Fama and French (1997). Organization capital is defined as $O_{i, t}=(1-\delta) O_{i, t-1}+S G A_{i, t}$, where $S G A$ is Selling, General and Administrative Expenses (Compustat item 189), following Lev and Radhakrishnan (2004). We chose $\delta=0.2$. In the portfolio sorts, we only include firms where $O_{i, t}>0$. 
Table 5: Robustness: 5 portfolios sorted on OC/A

\begin{tabular}{|c|c|c|c|c|c|c|}
\hline Portfolio & Lo & 2 & 3 & 4 & $\mathrm{Hi}$ & Hi-Lo \\
\hline \multirow[t]{2}{*}{$E\left(R_{i}\right)-r_{f}(\%)$} & 5.50 & 6.79 & 7.06 & 8.29 & 9.32 & 3.82 \\
\hline & $(2.89)$ & $(2.94)$ & $(2.67)$ & $(2.57)$ & $(2.64)$ & $(1.46)$ \\
\hline$\sigma(\%)$ & 17.32 & 17.62 & 16.02 & 15.44 & 15.81 & 8.74 \\
\hline \multirow[t]{2}{*}{$\beta_{M K T}$} & 1.06 & 1.08 & 0.98 & 0.91 & 0.93 & -0.13 \\
\hline & $(0.02)$ & $(0.02)$ & $(0.02)$ & $(0.03)$ & $(0.03)$ & $(0.03)$ \\
\hline \multirow[t]{2}{*}{$\alpha(\%)$} & -1.36 & -0.17 & 0.70 & 2.40 & 3.30 & 4.66 \\
\hline & $(0.81)$ & $(0.80)$ & $(0.75)$ & $(0.97)$ & $(1.03)$ & $(1.41)$ \\
\hline$R^{2}(\%)$ & 92.58 & 92.13 & 93.10 & 85.86 & 85.37 & 5.51 \\
\hline \multirow[t]{2}{*}{$\beta_{M K T}$} & 1.09 & 1.05 & 1.01 & 0.95 & 0.96 & -0.13 \\
\hline & $(0.02)$ & $(0.02)$ & $(0.01)$ & $(0.02)$ & $(0.03)$ & $(0.03)$ \\
\hline \multirow[t]{2}{*}{$\beta_{S M B}$} & -0.05 & 0.03 & -0.10 & -0.21 & -0.01 & 0.04 \\
\hline & $(0.03)$ & $(0.03)$ & $(0.02)$ & $(0.03)$ & $(0.03)$ & $(0.04)$ \\
\hline \multirow[t]{2}{*}{$\beta_{H M L}$} & 0.07 & -0.08 & 0.00 & -0.02 & 0.09 & 0.02 \\
\hline & $(0.04)$ & $(0.04)$ & $(0.03)$ & $(0.05)$ & $(0.04)$ & $(0.07)$ \\
\hline \multirow[t]{2}{*}{$\alpha(\%)$} & -1.82 & 0.37 & 0.81 & 2.80 & 2.66 & 4.48 \\
\hline & $(0.68)$ & $(0.66)$ & $(0.60)$ & $(0.77)$ & $(0.85)$ & $(1.19)$ \\
\hline$R^{2}(\%)$ & 92.87 & 92.39 & 93.62 & 88.07 & 85.67 & 5.76 \\
\hline
\end{tabular}

Table $\overline{5 \text { shows asset pricing tests for } 5 \text { portfolios sorted on organization capital over assets }}$ (Compustat item 6) relative to the industry. We classify firms into 17 industries, according to Fama and French (1997). The portfolios SMB and HML refer to a portfolio long small and short large stocks and a portfolio long value (high $\mathrm{BE} / \mathrm{ME}$ ) and short growth (low BE/ME) stocks, as defined in FF1993. Organization capital is defined as $O_{i, t}=(1-\delta) O_{i, t-1}+S G A_{i, t}$, where $S G A$ is Selling, General and Administrative Expenses (Compustat item 189), following Lev and Radhakrishnan (2004). We chose $\delta=0.2$. We only include firms in the portfolio construction process if they have at least 5, non-missing, non-zero values of SG\&A Expenditures as well as $O_{i, t}>0$. The sample period is January 1970 to December 2006. Standard errors (reported in parenthesis) are computed using the Newey-West estimator allowing for 1 lag of serial correlation in returns. All numbers are annualized by multiplying by 12 . 
Table 6: Robustness: sensitivity to the depreciation rate

\begin{tabular}{cccccc}
\hline \hline & $\delta=0.1$ & $\delta=0.2$ & $\delta=0.3$ & $\delta=0.4$ & $\delta=0.5$ \\
\cline { 2 - 6 }$E\left(R_{H i}-R_{L o}\right)(\%)$ & 5.01 & 4.66 & 3.84 & 4.07 & 4.35 \\
& $(1.49)$ & $(1.37)$ & $(1.27)$ & $(1.25)$ & $(1.27)$ \\
\cline { 2 - 6 }$\alpha_{H i}^{c a p m}-\alpha_{L o}^{\text {capm }}(\%)$ & 6.29 & 5.50 & 4.42 & 4.50 & 4.69 \\
& $(1.45)$ & $(1.37)$ & $(1.26)$ & $(1.24)$ & $(1.26)$ \\
$\alpha_{H i}^{f f 3}-\alpha_{L o}^{f f 3}(\%)$ & 6.44 & 5.82 & 5.27 & 5.60 & 5.85 \\
& $(1.14)$ & $(1.10)$ & $(1.04)$ & $(1.01)$ & $(1.01)$ \\
\hline \hline
\end{tabular}

Table 6 shows differences in expected returns and alphas for the long high organizational capital and short long organizational capital strategy under different assumptions about the depreciation rate. We classify firms into 17 industries, according to Fama and French (1997). The portfolios SMB and HML refer to a portfolio long small and short large stocks and a portfolio long value (high BE/ME) and short growth (low BE/ME) stocks, as defined in FF1993. Organization capital is defined as $O_{i, t}=(1-\delta) O_{i, t-1}+S G A_{i, t}$, where $S G A$ is Selling, General and Administrative Expenses (Compustat item 189), following Lev and Radhakrishnan (2004). We vary the depreciation rate between $\delta=[0.1,0.5]$. In the portfolio sorts, we only include firms where $O_{i, t}>0$. The sample period is January 1970 to December 2006. Standard errors (reported in parenthesis) are computed using the Newey-West estimator allowing for 1 lag of serial correlation in returns. All numbers are annualized by multiplying by 12 . 
Table 7: Parameters

\begin{tabular}{|c|c|c|c|c|c|c|c|c|c|c|c|}
\hline Parameter & $\mathrm{r}$ & $\mathrm{a}$ & $\lambda_{\theta}$ & $\mu_{\theta}$ & $\sigma_{\theta}$ & $\lambda_{x}$ & $\kappa_{x}$ & $\sigma_{x}$ & $\kappa_{\varepsilon}$ & $\sigma_{\varepsilon}$ & $c$ \\
\hline value & 0.06 & 0.012 & 0.012 & 0.01 & 0.125 & -1.75 & 0.1 & 0.15 & 0.2 & 1 & 13 \\
\hline
\end{tabular}

Figure 2: Solution
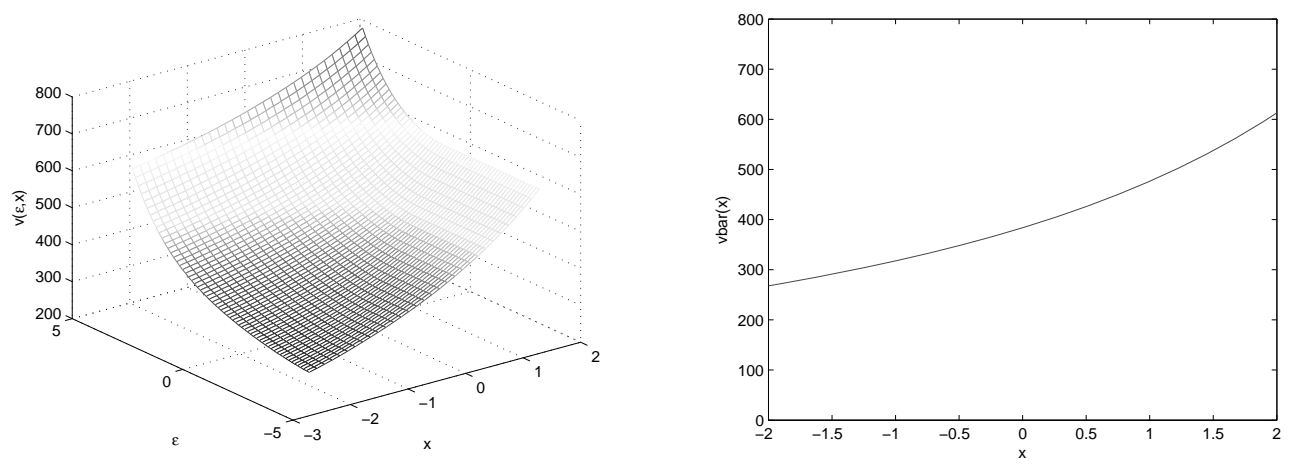

$$
v(\varepsilon, x)
$$

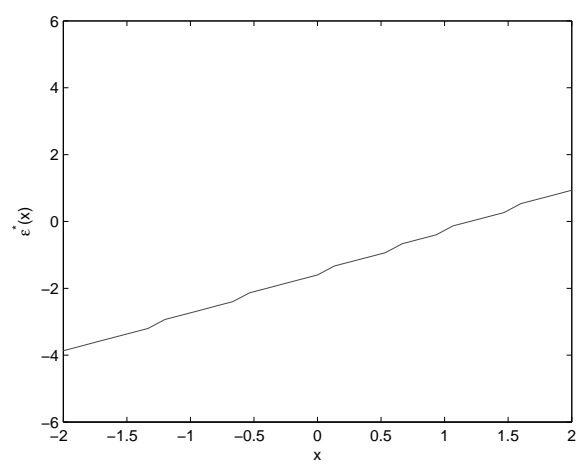

$$
\varepsilon^{*}(x)
$$

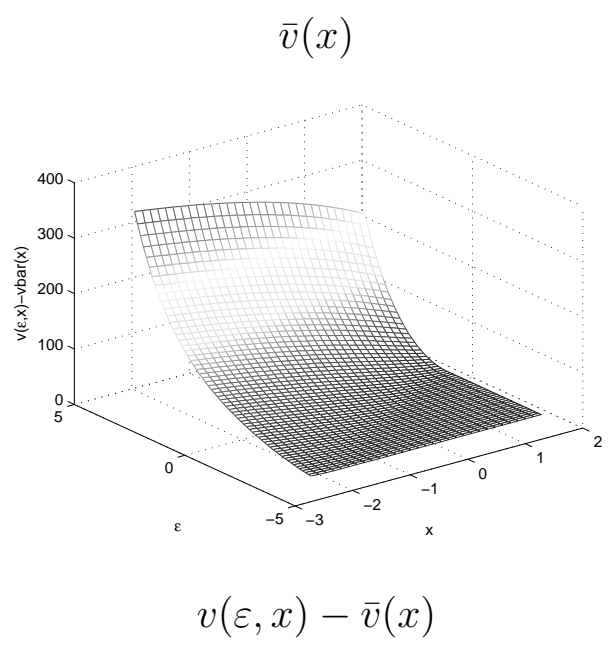


Table 8: Simulation Results: 5 portfolios sorted on OC/A

\begin{tabular}{|c|c|c|c|c|c|c|}
\hline Portfolio & Lo & 2 & 3 & 4 & $\mathrm{Hi}$ & Hi-Lo \\
\hline$E\left(R_{i}\right)-r_{f}(\%)$ & 6.99 & 8.23 & 9.08 & 9.95 & 11.30 & 4.31 \\
\hline$\sigma(\%)$ & 13.75 & 13.96 & 14.11 & 14.28 & 14.58 & 3.43 \\
\hline$\alpha(\%)$ & -2.19 & -1.07 & -0.30 & 0.48 & 1.68 & 3.87 \\
\hline$t$ & -11.96 & -6.47 & -1.84 & 2.68 & 7.85 & 10.99 \\
\hline$\beta^{M K T}$ & 0.97 & 0.98 & 1.00 & 1.01 & 1.02 & 0.05 \\
\hline$t$ & 77.10 & 86.76 & 86.91 & 81.23 & 69.05 & 2.22 \\
\hline$R^{2}(\%)$ & 98.42 & 98.71 & 98.71 & 98.55 & 97.99 & 6.05 \\
\hline
\end{tabular}

Table 8 shows moments and characteristics of portfolios sort on the ratio of organization capital to physical capital for simulated data. We simulate 3000 firms and allocate into quintiles every year. We report averages across 2000 simulations, each with a length of 100 years. Portfolio returns are constructed by value-weighting returns of individual firms by market capitalization. 


\section{Appendix}

\section{Numerical Solution}

We solve the PDE characterizing the solution using finite differences. In the continuation region, the function $v(\varepsilon, x)$ satisfies the $\mathrm{PDE}$

$$
0=\exp (\varepsilon)-\rho(\varepsilon) v-\kappa_{\varepsilon} \varepsilon v_{\varepsilon}+\frac{1}{2} \sigma_{\varepsilon}^{2} v_{\varepsilon \varepsilon}-\kappa_{x}(x-\bar{x}) v_{x}+\frac{1}{2} \sigma_{x}^{2} v_{x x}
$$

The continuation region is defined by $\varepsilon_{i, t} \geq \varepsilon^{*}\left(x_{t}\right)$, where $\varepsilon^{*}(x)$ solves

$$
v\left(\varepsilon^{*}(x), x\right)=v(x, x)-c \equiv \bar{v}(x)
$$

We discretize the state space, creating a $100 \times 100$ point grid for $(\varepsilon, x)$ and $\mathrm{v}$ with $h_{\varepsilon}=\Delta \varepsilon, h_{x}=\Delta x$. Then the following approximations can be used

$$
\begin{aligned}
v_{\varepsilon}\left(\varepsilon_{n}, x_{m}\right) & \approx \frac{v_{n+1, m}-v_{n-1, m}}{2 h_{\varepsilon}} \\
v_{\varepsilon \varepsilon}\left(\varepsilon_{n}, x_{m}\right) & \approx \frac{v_{n+1, m}+v_{n-1, m}-v_{n, m}}{h^{2}} \\
v_{x}\left(\varepsilon_{n}, x_{m}\right) & \approx \frac{v_{n, m+1}-v_{n, m-1}}{2 h_{x}} \\
v_{x x}\left(\varepsilon_{n}, x_{m}\right) & \approx \frac{v_{n, m+1}+v_{n, m-1}-v_{n, m}}{h^{2}}
\end{aligned}
$$

We then approximate the PDE as

$$
v_{n, m}=p_{n, m}^{d} v_{n-1, m}+p_{n, m}^{u} v_{n+1, m}+q_{n, m}^{d} v_{n, m-1}+q_{n, m}^{u} v_{n, m+1}+\exp \left(\varepsilon_{n}\right) \Delta t_{n, m}
$$


where

$$
\begin{aligned}
p_{n, m}^{d} & =\frac{\kappa_{\varepsilon} h_{\varepsilon} e_{n}+\sigma_{\varepsilon}{ }^{2}}{2 h_{\varepsilon}{ }^{2}} \Delta t_{n, m} \\
p_{n, m}^{u} & =-\frac{\kappa_{\varepsilon} h_{\varepsilon} e_{n}-\sigma_{\varepsilon}{ }^{2}}{2 h_{\varepsilon}{ }^{2}} \Delta t_{n, m} \\
q_{n, m}^{d} & =\frac{\kappa_{x} h_{x}(x-\bar{x})+\sigma_{x}{ }^{2}}{2 h_{x}{ }^{2}} \\
q_{n, m}^{u} & =-\frac{\kappa_{x} h_{x}(x-\bar{x})-\sigma_{x}{ }^{2}}{2 h_{x}{ }^{2}} \\
\Delta t_{n, m} & =\frac{h_{\varepsilon}{ }^{2} h_{x}{ }^{2}}{\sigma_{\varepsilon}{ }^{2} h_{x}{ }^{2}+\sigma_{x}{ }^{2} h_{\varepsilon}{ }^{2}+\rho\left(\varepsilon_{n}\right) h_{\varepsilon}{ }^{2} h_{x}{ }^{2}}
\end{aligned}
$$

Note that care must be taken when choosing $\left(h_{\varepsilon}, h_{x}\right)$ to ensure that the probabilities are non-negative at all points in the grid. Alternative differencing schemes that produce positive probabilities can also be used.

Using an initial guess for $\mathrm{v}$, say $v^{i}$, we recursively iterate on $\mathrm{v}$ until convergence:

$$
\begin{gathered}
v_{n, m}^{i+1}=\max \left[p_{n, m}^{d} v_{n-1, m}^{i}+p_{n, m}^{u} v_{n+1, m}+q_{n, m}^{d} v_{n, m-1}^{i}+q_{n, m}^{u} v_{n, m+1}^{i}+\exp \left(\varepsilon_{n}\right) \Delta t_{n, m},\right. \\
\left.v^{i}\left(\varepsilon=x_{m}, x_{m}\right)-c\right]
\end{gathered}
$$

We impose reflecting barriers on $(\varepsilon, x)$ at the boundaries of the grid. This reduces to $v_{0, m}=v_{1, m}, v_{N, m}=v_{N-1, m}, v_{n, 0}=v_{n, 1}, v_{n, M}=v_{n, M-1}$ since there is no discounting at the boundary. 